\title{
How does an athlete's heart react to studying at university?
}

\author{
Tatiana Popova*, Yurj Koriukalov, Olga Kourova, Vladimir Gurlev, Tatiana Khomykova \\ South Ural State University, 454080 Chelyabinsk, Russia
}

\begin{abstract}
I student-athletes; II - students and postgraduate students, not involved in sport. The functional status of the heart has been studied in three conditions: at rest, during the cognitive test, and under local static load (the wrist dynamometer). The electroencephalography has also been applied. Results demonstrated a statistical decrease in wrist endurance in all participants during the academic year. They proved fatigue development. A pronounced increase of heart rate and arterial blood pressure, as well as the increase of heart rate variability mode and stress index under local load and during the cognitive test, proved the development of the heart functional stress, especially in athletes. Electroencephalography data prove the central origin of adaptation reactions both to mental and to local muscular activity. Disease prevention and health improvement measures are necessary for university students actively involved in sport. One of such measures is relaxation exercises aimed at a decrease in functional stress.
\end{abstract}

\section{Introduction}

In sports physiology, there is a great issue of university students actively involved in sport. Studying at university is characterized by hypodynamia, a predominance of local load on the small groups of muscles, sleep and eating disorders, and psychoemotional stress.

Adaptation to academic load takes place in a quite active pace. Researchers from US Houston Medical School found out that studying activated reparation mechanisms responsible for the recovery of damaged DNA molecule fragments [1,2 ]. German scientists from the University of Dusseldorf revealed that intensive mental activity affected negatively the psychological status of studentsю It was manifested in a worsening of the psychological status during intensive academic load [3,4]. The authors [5,6] also revealed that regular physical load contributed to the adaptation of students to academic load.

The forecast of possible deviations in the functional status of students-athletes and timely correction is essential for health maintenance and academic progress. The literature contains various opinions, both positive [7,8 ] and negative [9], about the features of cognitive activity in athletes compared to non-athletes. The results of other researches prove that athletes demonstrate better psychophysiological data in terms of attention,

* Corresponding author: tati.popova2010@yandex.ru 
mental capacity, and short-term memory, while non-athletes are characterized by better attention volume and distribution [10-12].

A significant number of authors showed that the athletes' heart was characterized by more pronounced responses compared to non-athletes even in case of an insignificant load of a cognitive character. It explained the notion of "excessive adaptation". However, the features of adaptation mechanisms to various load in athletes require a comprehensive study.

Aim. The article deals with studying the adaptation of the athletes' heart to academic load in student-athletes aged 18-20 years (local muscle load and cognitive load).

\section{Materials and methods}

Two groups of participants have been studied: I - student-athletes (category I - master for sports), involved in acyclic sports (experimental group - 14 persons); II - students and postgraduate students, not involved in sport (control group - 15 persons). The research was conducted on voluntary informed consent of the subjects, in compliance with the protocol approved by the Ethical Board of the Russian Academy of Sciences.

The initial functional status of the heart, its status during the cognitive test, and under local static load before fatigue (wrist dynamometer, a force of 1/3 of the maximum) have been studied. Static wrist endurance (SWE) has been defined by the duration of maintaining load at the same level. As a cognitive test, the participants subtracted backward 5 and 2 by turn from 200 per 100 seconds. The assessment of the heart regulatory processes has been conducted using the heart rate variability data [2,13] obtained by 5 -minute electrocardiography. The following indicators have been taken into account: the most frequent value of R-R interval duration, i.e., mode (Mo); the range between the maximum and minimum values of cardiac intervals $(\Delta x)$; amplitude mode (AMo); stress index (SI). Stress index is an integral indicator, reflecting the centralization of heart rate control.

$$
\mathrm{SI}=\frac{\mathrm{AMo}(\%)}{2 \mathrm{Mo} \cdot \Delta x(\mathrm{c})}
$$

The electroencephalogram (EEG) was recorded in compliance with the 10-20 system (Neuron Spectrum equipment, Neurosoft, Russia). EEG sampling frequency was $250 \mathrm{~Hz}$. The spectral frequency indicators of theta, alpha, and beta rhythm were analyzed with the help of period analysis. Computer-assisted electroencephalography included spectral and correlation analysis performed by using the developer's software.

The processing of the data obtained was performed with Statistica 6.0 (StatSoft, the USA) and SPSS software. The arithmetic mean (M) of the ordered sample, the standard error of the mean (m), and the Student's t-distribution were calculated, while accepting the critical importance value for the statistical hypotheses verification to be 0.05 .

\section{Results and discussion}

The results obtained showed that the highest indicators of static wrist endurance (SWE) were registered in trained males (Table 1). At the end of the first semester and the academic year, the decrease of SWE indicators was revealed in all participants, especially in athletes in the first semester. These data prove the development of fatigue in all participants, including athletes, during the academic year.

Table 1. Changes in static wrist endurance in students during the academic year 


\begin{tabular}{|l|l|l|l|}
\hline \multirow{2}{*}{ Group } & \multicolumn{3}{|c|}{ SWE, s } \\
\cline { 2 - 4 } & Initial data & $\begin{array}{l}\text { At the end of the first } \\
\text { semester }\end{array}$ & $\begin{array}{l}\text { At the end of the academic } \\
\text { year }\end{array}$ \\
\hline Athletes & $50.54 \pm 5.01$ & $32.35 \pm 2.40^{*}$ & $33.41 \pm 0.32 *$ \\
\hline Non-athletes & $44.25 \pm 2.03 * *$ & $28.45 \pm 1.71^{*}$ & $24.25 \pm 0.31 *$ \\
\hline
\end{tabular}

Note: $*$ - significant differences compared to the initial data; $* *$ - between athletes and non-athletes; at $\mathrm{p}<0.05$

In athletes, HR and diastolic arterial pressure data at rest were lower compared to nonathletes (Table 2). During local static work with the wrist dynamometer, the increase of both systolic and diastolic arterial pressure was registered in all participants. The most pronounced pressor response was revealed in untrained males. In athletes, the increase of diastolic pressure was higher compared to untrained students. After mental work (the cognitive test) HR and arterial pressure data in all participants increased to a lesser extent compared to the data obtained after the local load.

Table 2. Changes in HR and arterial blood pressure before and after mental load and local muscular activity

\begin{tabular}{|c|c|c|c|c|c|c|c|c|c|}
\hline \multirow[t]{2}{*}{ Group } & \multicolumn{3}{|c|}{ HR (bpm) } & \multicolumn{3}{|c|}{$\begin{array}{l}\text { Systolic blood } \\
\text { pressure, } \mathrm{mmHg}\end{array}$} & \multicolumn{3}{|c|}{$\begin{array}{l}\text { Diastolic blood pressure, } \\
\mathrm{mmHg}\end{array}$} \\
\hline & Befor & $\begin{array}{l}\text { Cognitive } \\
\text { test }\end{array}$ & $\begin{array}{l}\text { Local } \\
\text { load }\end{array}$ & $\begin{array}{l}\text { Befor } \\
\text { e }\end{array}$ & \begin{tabular}{|l|} 
Cognitive \\
test
\end{tabular} & $\begin{array}{l}\text { Local } \\
\text { load }\end{array}$ & Before & $\begin{array}{l}\text { Cognitive } \\
\text { test }\end{array}$ & $\begin{array}{l}\text { Local } \\
\text { load }\end{array}$ \\
\hline \begin{tabular}{|l|} 
Athletes \\
\end{tabular} & $\begin{array}{l}65.2 \pm \\
2.2\end{array}$ & $=\begin{array}{l}67.4 \pm \\
2.9\end{array}$ & $\begin{array}{l}82 \pm \\
2.9^{*}\end{array}$ & $\begin{array}{l}102 \pm \\
2.3\end{array}$ & $\begin{array}{l}107 \pm \\
3.1\end{array}$ & $\begin{array}{l}129 \pm \\
3.1 *\end{array}$ & $\begin{array}{l}70 \\
\pm 1.8\end{array}$ & $\begin{array}{l}72 \pm \\
1.9\end{array}$ & $\begin{array}{l}85 \pm \\
1.9^{*}\end{array}$ \\
\hline $\begin{array}{l}\text { Non- } \\
\text { athletes }\end{array}$ & \begin{tabular}{|l}
$68.5 \pm$ \\
1.9
\end{tabular} & $\begin{array}{l}70 \pm \\
2.9\end{array}$ & $\begin{array}{l}83 \pm \\
1.0^{*}\end{array}$ & $\begin{array}{l}103.7 \\
\pm 4.4\end{array}$ & $\begin{array}{l}108 \\
\pm 2.8\end{array}$ & \begin{tabular}{|l|}
$127 \pm$ \\
$1.4^{*}$
\end{tabular} & $\begin{array}{l}70.6 \\
\pm 1.5\end{array}$ & \begin{tabular}{|l|}
$73.7 \pm$ \\
1.4
\end{tabular} & $\begin{array}{l}78 \pm \\
1 . \\
4 *\end{array}$ \\
\hline
\end{tabular}

Note: * - significant differences compared to the initial data; at $p<0.05$.

The analysis of heart rate structure proves similar changes in heart regulatory mechanisms for both types of activities. The statistical values of heart rate variability at rest showed the greater activity of the central sympathetic effects in untrained students compared to athletes (Table 3). For example, in athletes, Mo and $\Delta \mathrm{X}$ values (parasympathetic activity indicator) were higher, while AMo (sympathetic activity indicator) and SI were lower than in untrained students. After the local load, the increase of sympathetic effects on the heart in athletes was much higher than in untrained students with respect to AMo values.

Table 3. Changes in heart rate values after local load

\begin{tabular}{|l|c|c|c|c|}
\hline \multirow{2}{*}{ Group } & \multicolumn{4}{|c|}{ Values before load } \\
\cline { 2 - 5 } & Mo, s & $\Delta X, \mathrm{~s}$ & AMo, $\%$ & SI, c.u. \\
\hline Athletes & $0.80 \pm 0.11$ & $0.32 \pm 0.06$ & $28.12 \pm 1.01$ & $77.10 \pm 1.00$ \\
\hline Non-athletes & $0.80 \pm 0.10$ & $0.30 \pm 0.05$ & $36.14 \pm 2.01 * *$ & $86.50 \pm 9.05$ \\
& & \multicolumn{4}{|c|}{ After load } \\
\hline
\end{tabular}




\begin{tabular}{|l|l|l|l|l|}
\hline Athletes & $0.75 \pm 0.02$ & $0.20 \pm 0.01$ & $50.20 \pm 1.11^{*}$ & $105.10 \pm 6.07^{*}$ \\
\hline Non-athletes & $0.60 \pm 0.08^{*}$ & $0.20 \pm 0.05$ & $39.31 \pm 3.22$ & $115.27 \pm 9.11^{*}$ \\
\hline
\end{tabular}

Note: $*$ - significant differences compared to the initial data; $* *$ - between athletes and non-athletes; at $\mathrm{p}<0.05$.

After the cognitive load, there was an increase in the stress indicators of the central regulatory mechanisms, especially in untrained students. However, these changes were less pronounced compared to the local.

The analysis of electroencephalogram data revealed that athletes, compared to untrained students, were characterized by alpha-activity in the background recording with the eyes open accompanied by the significant rate index in the frontal areas of the brain hemispheres. In untrained participants, alpha-activity was registered mainly in the occipital region. The majority of participants were characterized by the predominance of alphaactivity in the left hemisphere.

In $30 \%$ of untrained participants and $60 \%$ of athletes, the development of fatigue under local muscular activity provoked a short-term increase of activity frequency accompanied by the depression of theta- and alpha-rhythm in the frontal areas of the cortex (fig. 1). The participants described this phenomenon as a feeling of overcoming fatigue resembling of a 'final burst' in sport.

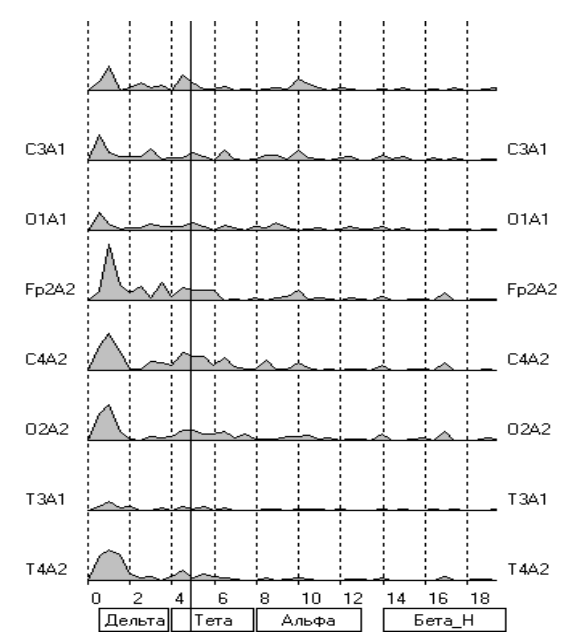

$\begin{array}{llll}\Delta & \theta & \alpha & \beta\end{array}$

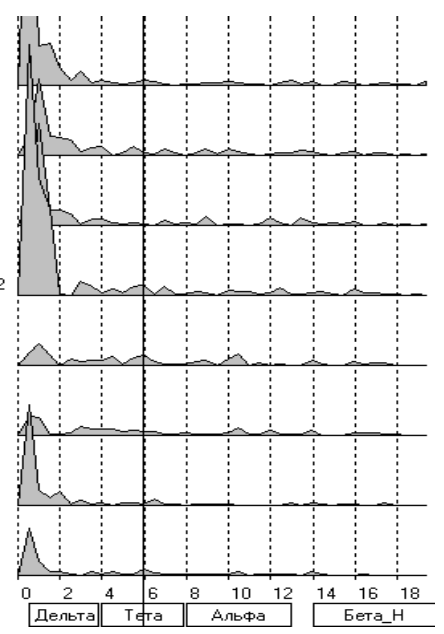

$\begin{array}{llll}\Delta & \theta & \alpha & \beta\end{array}$

Fig. 1. The decrease in theta-power in the frontal and central areas (F2 and C4) under local muscular activity in an athlete.

Compared to untrained participants, athletes were characterized by the increase in alpha-activity both in the frontal and occipital areas of the brain hemispheres. This proves the synchronicity of bioelectric activity in these areas.

Therefore, sport contributes to an increase in the functional rhythmicity of the nervous system, synchronization, and generalization of the brain bioelectrical activity.

Regular physical exercises activate adaptation. Therefore, it can be supposed that local muscular activity should not provoke pronounced changes in the body. However, our data prove a significant reaction of the heart and central nervous system to local static load in 
athletes. The increase of diastolic pressure in athletes under load was even higher compared to untrained participants. This proves a strong, distributed vessel reaction in athletes.

The heart reaction to mental load was lower. However, the statistical data of heart rate indicated functional stress of the heart under mental and, especially, local muscular load. According to the data of wrist endurance, as well as of heart performance at rest and under local static load, it can be concluded that there is the development of fatigue and functional stress in students during the academic year [14].

EEG data prove the central origin of adaptation reactions both to mental load and local muscular activity. The data obtained can prove the mechanism of the central origin of functional status in trained people. In athletes, this status is provided by a high level of physiological performance during physical activity $[15,16]$. However, it also indicates a risk of maladaptation.

We demonstrated previously that athletes coped more effectively with cognitive test than untrained students. The analysis of the functional status in $2^{\text {nd }}$-year or $3^{\text {rd }}$-year students involved in relaxation revealed that there was an improvement of psychophysiological functions compared to their peers not involved in relaxation $[17,18]$. However, to provide better academic performance, it is necessary to mobilize resources and a certain degree of the functional stress of the heart and central nervous system typical for student-athletes. Such mobilization is justified when it comes to physical load in sport. However, it can contribute to the development of functional stress under academic load.

\section{Conclusions}

To prevent functional stress in University students actively involved in sport, it is necessary to introduce disease-preventing and health-improvement measures such as relaxation exercises. In trained students, the data of the psychophysiological status of the body prove their better potential in mental activity. It can be unlocked thanks to the psychophysical correction of the body as a part of the educational process.

Conflict of interest: none declared.

\section{References}

1. L. Cohen, G.D.Marshal, L.Cheng et.al., Journal of Behavioral Medicine, 23(6), 531544 (2000)

2. S.I. Soroko, A.A. Aldasheva, Human Physiology, 38(6), 78-86 (2012)

3. R Deinzer, N. Granrath, H. Stuhl, L. Twork, H. Idel, B. Waschul, A. Herforth, Brain BehavImmun, 18, 458-467 (2004)

4. S. Kumar, R. Hultman, D. Hughes, N. Michel, B. M. Katz, K. Dzirasa. Nature Communications (Published Online, 2014)

5. H.A Synkova., N.G. Blinova, Valeology, 1, 64-70 (2010)

6. Y.I. Koryukalov, T.V. Popova, O.G. Kourova, Acta kinesiologiae, University of Tartu Press, 20, 144 (2014)

7. L.V. Kapilevich, Ye.V. Zamulina, Reports of the VI Siberian Physiological Congress (Printerspress, Barnaul, 1, 97-98, 2008)

8. M.B. Gurova, L.V. Kapilevich, T.S. Matrosov, Bulletin of Tomsk State University, 345, 171-172 ( 2011)

9. O.L. Tarasova, L.A. Varich, L.A. Proskuryakova, Reports VI Siberian physiological congress (Printerspress, Barnaul, 2, 67-68, 2008)

10. V.S. Ashanin, Slobozhansky sports science bulletin, 5, 164-166 (2002) 
11. V.B. Pavlenko, V.V. Chernyi, D.G. Gubkina, Neurophysiology, 41(5), 400-408 (2009)

12. G.G. Knyazev, A.N. Savostyanov, E.A. Levin, Int. J. Psychophysiol., 57(3), 175-180 (2005)

13. R.M. Baevsky, Yu.A. Kukushkin, Occupational medicine and industrial ecology, 3: 3034 (1995)

14. S.A. Gordeev, Human Physiology, 33(4), 11-17 (2007)

15.Z.B. Belotserkovsky, B.G. Lyubina, V.A. Gorelov, I.V. Ugolkova, Human physiology, 30(1), 124-131 (2004)

16. T. Giesbrecht, E.M. Jongen, F.T. Smulders, H.J. Merckelbach, Nerv. Ment. Dis., 194(5), 362-368 (2006)

17. T.V. Popova, Yu.I. Koryukalov, O.G. Kourova, Theory and practice of physical culture, 8, 20-23 (2006)

18. A.S. Kuznetsov, Z.M. Kuznetsova, Russian Journal of Physical Education and Sport, 14(4), 5-7 (2019) 